\title{
The Contemporary Significance of Culture and Education Research of Heluo Martial Art
}

\author{
Ming-Hua ZHOU ${ }^{1, a}$, Nan CHENG ${ }^{2, b}$ \\ ${ }^{1}$ China,Henan Province,Luoyang City,Luoyang Normal University of Sport \\ ${ }^{2}$ China,Henan Province,Luoyang City,Luoyang Normal University of Sport \\ aync-zhmh@163.com, \\ bchengnan1107@163.com \\ Corresponding author:Ming-Hua ZHOU
}

Key words: Heluo; Martial Art Culture; Educational Research; Contemporary Significance

\begin{abstract}
Under the influence of advanced and modern western culture, domestic people brought the great difficulty to the martial arts culture to highlight its value. The martial arts provide good quality and important life ideas, so its education is very important. We can use culture as the source and media to give the youth the spirit of the nation and the noble personality as well as good moral character. For teenagers, accepting the culture is the foundation, which may have a profound educational influence. In Heluo area, its martial arts culture has a long history, facing the development times of global economic and diversify culture, this paper launches the research of the contemporary significance involving Heluo cultures of martial arts and education.

Chinese martial arts exist as the important carrier in the national cultures, Heluo culture of martial art is one of the Chinese traditional culture essences and the reflection of martial arts soul. So in the cultural pattern of competition, if we only cognize Wushu as a sport, it will underline the flaw and the insufficiency of the Wushu culture. We shall improve Wushu cognition to the cultural height and level, and completely reveal its cultural connotation, beauty and value. It is not only fitness and self-defense, but also can cultivate one's morality and cultivation, and further to improve the human life. If we want to transport the high quality of the traditional martial arts culture to the world, we need to use the means of innovation, which has a strong persuasion, appeal and penetration. In the process of transmission, you can also use the way of personal perception of martial arts to experience the concept of martial arts culture.
\end{abstract}

\section{Study the Martial Arts Culture at Heluo Area}

\section{Shaolin Martial Arts Culture}

Shaolin Wushu is born in Shaolin Temple (Chan Zong cradle), where integrated Heluo culture and Buddhist, which has a close relationship with Heluo culture in its continuous development process. Under the influence of this culture, combined with the important elements of Heluo culture, it formed the unique martial arts culture. The martial arts culture is formed in the big environment, especially influenced by its Chanzong culture, so that the martial arts culture has unique colors. Through Zen Buddhism culture, which was constantly permeated with the Heluo culture in the Shaolin martial arts culture, the monks will use equipment in daily life, for example, Qimei Stick and Buddhist monk's staff. In addition, the influence of Zen Buddhism culture on the non-mistake culture was also reflected on routines, which were generated by referring to that of Buddha, Buddhism and other tasks. For example, the arhat boxing, clenched fist and small fork rod, among which Lohan, diamond and Inuyasha belong to the content of Buddhism, which completely show integration between Buddhism and Shaolin martial arts. Different techniques and actions such as tuck, sit cross legged or three pillow are borrowed from many actions and states of Buddhist arhat. Thus, the Buddhist culture of Shaolin Temple has a deep influence on the culture of martial arts. 


\section{Taijiquan of Martial Arts Culture}

Influenced by Heluo culture, Taijiquan regards Taiji Yin Yang theory in "book of changes" and meridian theory of Chinese medicine as the theoretical foundation, highlights the philosophy of "harmony between man and nature", and combined with the folk boxing strengths, and formed a new martial art of Tai Chi Chuan, with characteristics of rigid, flexible, light, speed and others. Using Taijiquan original theory recorded by the text is " general song of boxing", the Tai Chi derived a lot of schools in its constant inheritance, includes Chen differentiating Yang and $\mathrm{Wu}$, and then refined into Wu, sun and others, but all formed the boxing styles with its own characteristics. In order to do further popularization, the State Physical Culture and Sports Commission has organized experts to prepare Taijiquan repertoires which is convenient to public learning. Nowadays, it was spread around more than 100 countries or regions, it is a project of martial arts movement which has many participants. With its rich cultural connotation of martial arts, it becomes a treasure house of Chinese culture, and now it is the culture that pursuit by global world. the Taijiquan employ body to spread culture, breaking the obstacles and limitations of language communication. With proceeding a wide range of communication around the world, more highlights the cultural spirit and connotation of martial arts.

\section{Preserve One's Health of Martial Arts Culture}

\section{Namo Boxing}

Namo boxing arisen from the Quanzhen Taoism of namo pie, built in the time of Tan Chuduan doing monasticism at Luoyang, who is one of seven people, combined with Heluo culture, regard the harmony between man and nature as the guidance thought, compiled this boxing by drawing Chinese purification and alchemy essentials, it actually belongs to internal boxing, proceed gas practice and internal injury treatment in the disciples, so that the internal body system can be practiced, and improve their great compression ability, using cognition and perception of boxing principle to achieve binding targets of boxing way. Chamfer of parent of preserve one's health mainly guided the gas. It can cultivate and prolong life, and attach importance on practice of gas in practices, using the practice of gas to reach meridian dredging and smooth of gas and blood, and regulate the body to achieve the balance of yin and Yang, which has effect of crank and life extension. The relevant action of boxing namo, mainly are brace and pull, its actions were created in accordance with the relevant navigation map. To lead the internal gas to realize that body can carry out days and weeks' operation, with some methods and actions, to assist the human be easy to cultivate the spirit of harmony and blood, so as to achieve the efficacy of health.

\section{Changjia Boxing}

The first referenced Heluo culture, absorb some Taoist alchemy to practice gas from it, the human body achieve the combination of the movement of the gas and martial arts. More noted yin yang theory of gas and shape, especially regard traditional Chinese medicine involving the meridian and visceral doctrine as the basis, and combined with some skills in boxing, and study important relationship' of yin and yang balance. The two of human meridian, yin and Yang, are not only exist contact, and also has the role of interaction and the basic laws of continuous movement. Its theory overview the relationship between the techniques of action and the theory of yin and Yang, and produced urged role and influence to the weakness of boxing, effectively promote the perfect or promotion of boxing skills.

\section{The Contemporary Significance of Wushu Culture in Education}

\section{Analysis Based on Strategic Height}

In today's world, the development of global economic prompted the integration of different cultural and economic, politics among different regions, its culture manifest its status and role in a competition of comprehensive national strength. The less of the cultures directly affects the fate of national culture in tits development, especially the traditional culture of our country, it is an 
important manifestation of the national spirit, which shows the creativity and the cohesive force. The development of the country is also reflected in the conflict and contest of different cultures, Our Chinese martial arts need to push it into the global culture in the development of modernization. With the advent of the era of economic and economic integration, the consumers' consumed ways and concept of survival have changed. Under the global cultural competition, in order to narrow the gap between the cultures, we should transform the traditional culture into modern culture, under the grim situation, martial arts need to not only adapt to modern culture but also to retain the national style, actually which is from a great challenge of traditional culture.

\section{Analyze it under the Background of the Whole Human}

Chinese martial arts culture is an important carrier of national culture, it is a combination of essences of many traditional cultures. Push qualified culture to the world, Chinese Martial art is not only a carrier of national culture, is also a carrier of national excellent culture, if it wants to provide benefits to human beings, it should reflect the value of martial arts, made martial arts entering into the world truly, not to stay on the technical level. Its promotion started from some overseas Chinese, though has been nearly 200 years, but culture, national characteristics of martial arts have not acquired enough attention and a wide range of promotion, the relevant courses of Chinese martial art rarely open in foreign countries, in a sense, the research of Wushu culture is particularly important, but need many staffs and basic martial arts experts and scholars pay a lot of effort, to truly implement the martial arts culture into practical work. Regard cognitive martial arts as the main content of the national policy, is conducive to the country or the nation to make progressive contributions. Chinese martial arts culture is an important carrier of national culture, it is a combination of many traditional culture with the essence of. The quality of the culture to the world, Chinese Wushu is not only a carrier of national culture, is a carrier of national culture, to provide benefits to human beings, we should reflect the value of martial arts, martial arts to the world that really true, not to stay on the technical level. The promotion from some overseas Chinese have started, though has been nearly 200 years, but the martial arts culture, national characteristics you have not been enough attention and promotion of a wide range of martial arts, the relevant courses in China rarely open in foreign countries, in a sense, the research of Wushu culture is particularly important, but need to the staff has been basically a lot of martial arts experts and scholars pay a lot of effort, to truly implement the martial arts culture to practical work. The cognitive martial arts as the main content of the national policy, which is beneficial to make progressive contributions for the country or the nation.

\section{The Effective Strategies of Inheritance of Heluo Wushu Culture in the Martial Arts Education}

\section{The Correct Positioning and Cognition of Heluo Wushu}

Wushu has been born more than a thousand years, along with the development of society and the age, martial arts shows differentiate content in the aspects of connotation and function, especially in the process of development, transformed from the military function to sports function. Until now, it clears the property of sports, in which to enhance human quality and physical fitness. Martial arts not only belong to sports, it is also higher than sports, and there is a big difference with the western culture. In 2009 it adjusted the definition of Wushu, regard Chinese culture as the theoretical basis, and the attack method as the basic content, routines and combat as main forms of traditional sports. Society has gradually attached importance on the connotation of the martial arts culture, pay more attention to the pursuit and improve their own personality. Other projects are not comparable with Martial arts in the sports project, its cultural connotation has a distinct philosophical and scientific nature and artistic. Under the continuous promotion of Chinese culture, the traditional national culture can not be short. Therefore, it need to correct cognition and locating the importance of martial arts of Heluo culture. 


\section{Use Policy Supports to Enhance the Status of Martial Arts in Education}

Martial arts need to continue to develop in the community, but the cultural heritage needs to be supported by national policy and attention, and committed to the correct position to be inherited in the education of the martial arts. Early in the Shanghai national education combined the fourth conference proposed that school education should add to teach martial arts and, also advocating Wushu as the Chinese special movement, and increased the degree of importance of martial arts in sports year by year, the formulation and implementation of national policies promote the its development. However, martial arts will be included in the scope of sports at the contents of the file, so becomes a physical contact sport in the sports in the sports gathering. The Ministry of education followed pointed out that, P.E. curriculum should increase the amount of some related content of martial arts, the martial arts education of Chinese culture and national spirit can be propagated in an important way, in the world culture and competition of market economy, the state should pay more attention to the role of Wushu in the education of traditional culture, can no longer proceed physical exercises under western sports theory. martial arts education is also a form of martial arts culture, and an important platform of national cultural heritage, the education of Wushu in China formulated a policy, and martial arts education can not be committed into physical education, to create exclusive brands belonging to Wushu education, to the form relevant policies from the perspective of cultural heritage, and then clear the important role of Wushu education in sports culture, directly and effectively enhance its position in education.

\section{Clear the Specific Content of the Inheritance of Wushu Culture}

To clear that Wushu culture heritage important contents in different stages of education, because education has many layers, and belongs to a gradual process, the implementation of martial arts culture education for students, at different stages will affect students' physical and mental development. For example: in the primary school, students are full of enthusiasm, but under the influence of adverse factors, for thing of self-like with high enthusiasm. According to the characteristics of students in physical and mental development, teachers should be appropriate to teach students in the implementation of the culture and education of Wushu, and master some basic interest and Wushu conscience, standardized their Wushu behavior. Therefore, it is needed to clarify the specific content inherited by Wushu culture and promote the development of Wushu Culture in the world culture.

\section{Conclusion}

The happy and unique Wushu culture formed by the interact between Chinese Wushu and traditional ethnic culture, is also an important branch of Chinese culture, exist in an important system of independence and integrity of culture, its core connotation is an important symbol of Wushu culture, especially human's cognition for martial arts, so it can not be simply regarded as a sport, and it need to do clear cognition to Wushu, it is a tangible form of culture, collected a variety of culture, should be greatest inheritance China Heluo culture of Wushu.

\section{References}

[1] Qiu Pixiang. The contemporary significance of Wushu culture and education research [J]. sports science, 2010,2 (15): 164

[2] Qiu Pixiang, Ma Wenguo. Contemporary significance of Wushu culture Study and education research [J]. Journal of physical education, 2010,4 (6): 85-89 (30): 18 - 20.

[3] Guo Shufen. Heluo culture research from the perspective of inheritance and development of Folk Wushu in Luoyang area [J]. Chengdu Institute of physical education, graduate student degree thesis, 2013,5 (20) is: 1 - 31.

[4] He Yanqiang. Research on the inheritance of Wushu Culture in Wushu education [J]. Henan 
University master's degree thesis, 2013,5 (26): 1 - 37

[5] Guo Debing. Research on the development of Wushu Culture in Central China [J]. Journal of Shandong Sports Institute, 2010, 5 (10): 113 - 115 